\title{
Online Learning: An Enthusiastic Approach
}

\author{
Aleksandra Holubowicz
}

\begin{abstract}
The text identifies the opportunities that online interaction sessions provide. The author does not enumerate the general advantages of distant learning that occurs via the internet, but she introduces the strategies she finds superior to the conventional face-to-face mode, as evident in her teaching practice. These refer to certain technicalities that enable completion of certain tasks more effectively than in the real classroom as well as to the possibility of creating a more egalitarian relationship between the teacher and the students.
\end{abstract}

Key words: Learner's autonomy, online learning, learner-centeredness, Attention Deficit Disorder

The difficulties that all the stakeholders in education face due to the e-learning mode are many and thus they have become a recurrent motif of our daily complaints, which, in the Central/Eastern Europe account for a source to rely on while trying to perform the phatic function of communication. We are able to enumerate technical glitches that spoil what was to be an excellent lesson or how lack of human contact affects the performance of all involved, not to mention background noises due to raucous dormitory roommates or our neighbors implementing a major reconstruction of their apartment at the time that exactly coincides with our teaching/learning schedule. On the other hand, after initial skepticism of going online full-time I recognize a number of benefits of working from home. I do not mean only the fact that such a mode offers a relief to introverts, but certain unquestionable advantages of e-learning emerge. Ample literature on the issue discusses the positive sides of both online and blended-learning, but the goal of the article is to focus on those aspects that can be perceived as introducing a substantial improvement to the quality of language lessons as compared to the in-class mode as manifested in my teaching practice. These encompass strictly didactic components and the psychological impact: the former include semantic content, particular tools applied while using a given method or approach and the effects, whereas the latter refer to the nature of relationships between the teacher and the student as well as within the peer group.

The approach I normally assume aims to achieve the highest possible degree of learner-centredness. It involves an eclectic collage of various methods and techniques depending on the target group. Since all my courses, including General English and those whose purpose is to prep students for the internal B2 exam at Charles University, are predicated upon boosting speaking skills, my professional experience demonstrates that in order to engage students in a genuinely interesting conversation it is worth adhering to one of the major principles underly- 
ing Community Language Learning - "making language acquisition meaningful on a personal and intellectual level" (Lentzner, 1979, p. 103). To achieve that I rely on authentic materials, at all proficiency levels I teach varying from A2 to C2.

I have also recently realized that what I understood by emphasizing the development of speaking skills I actually enable students to practice interaction and mediation, as identified in the recent research on language learning/teaching. Kris Peeters in his presentation The Place and Importance of Mediation in Language Learning and Teaching outlines the general methodology

- „a double aim and a paradigm shift action-oriented approach: learners as social agents with agency in the learning process (learner engagement and autonomy)

- plurilingual, pluricultural competence: developing learner's plurilingual repertoire communicative activities / strategies to perform purposeful communicative tasks Reception (reading, listening), Production (writing, speaking), Interaction,

- Mediation 'can do'-descriptors: needs-based, (self-)assessment on communicative criteria, increases learner reflection and motivation" (Peeters, 2020)

The aforementioned objectives can well be achieved in the online mode during interactive sessions, sometimes more effectively than while working in person. This particularly refers to promoting learners' autonomy, not only due to the necessity to adapt the cognitive process to the lock-down related restrictions. Even though many class members complain about lack of face-to-face contact, in fact, a greater degree of personalization is possible for various reasons (e.g. the necessity of mail correspondence, undivided attention in the breakout rooms, a smaller number of students in a group). Perhaps these factors lead to enhancing students' participation in shaping the content of the course, which allows for a greater degree of personalization: it can be tailored to the needs of the specific group.

Additionally, it boosts production, interaction and mediation skills, often times more successfully than in the off-line mode I hypothesize that the increased willingness to choose authentic materials or suggesting topics for discussion results from the technological tools applied to support learner-centered approach in distance learning. Inasmuch as a variety of so-called "fun" activities including playing hangman on the internet might serve to supplement the learning process with some groups, I usually stick to simple applications such as google docs. I resort to these not only in distance learning: in general, shared documents enable amassing vocabulary that students actually need while talking. Naturally, they are encouraged to run their own vocabulary lists, but one document accessible to all group members lends itself to registering the material covered and thus a sense of progress even though most of the time is dedicated "only to talking": with 
a co-created file, the Ss are offered tangible proof of what their learning process embraces.

The usual speaking procedure involves providing students with stimulating materials (usually beforehand in the case of texts/videos to process before the beginning of the class) and follow-up questions. I assume the role of the coach/facilitator and thus I overhear what they discuss in their groups and offer the necessary vocabulary either translation to English, correction of a phrase used by the Ss or a synonym in order to assist in students' enrichment of active vocabulary. In class such a practice requires hovering over students with a notebook, taking notes in hand and later transferring these to the board and the shared document so that we can all keep track of the vocabulary/structures that have been covered.

The Teacher's (T) task proves much easier while working online, especially with applications that enable dividing students to breakout rooms (including zoom). While students (Ss) are discussing the questions that are provided, $\mathrm{T}$ is able to record much more mistakes and offer the necessary vocabulary than in class, in which case, a number of expressions are lost due to the quality of handwriting while jotting down the information under the pressure of time. Thus, while students are completing their oral tasks, I can record their sentences containing mistakes in our shared document, and a relevant grammar exercise is created on the spot. Students can be asked to improve the utterances either during the interactive session or as homework. Except for common misuse of grammar points, I jot down repetitions or colloquial expressions, which allows for encouraging them to work on their style. For instance, they are motivated to search for synonyms to replace the basic words such as "big", "get" or "go" as well as eliminating use of simple intensifiers (including "very, very") in academic contexts.

Another obstacle while meeting in person is noise in the classroom generated by parallel discussions in groups, which exists as a distractor to some Ss and Ts alike. On the one hand, in a successful class lively communication occurs, which, if the participants are involved, is rarely a quiet one. On the other, however, those who manifest hypersensitivity, including individuals with ADD (Attention Deficit Disorder), will find a noisy classroom chaotic and exhausting. As Terry Matlen observes in her boook The Queen of Distraction "many women with ADHD live with extreme sensitivity to sight, sound, smell, taste, and touch. This high level of sensitivity to stimuli can be overwhelming for them in a number of situations that are humdrum for other people." (Matlen, p. 130) Matlen focuses on women in her book, which offers a mix of theory instrumental in comprehending the mechanics of ADD/ADHD as well as practical tips addressed to women with the aforementioned conditions on how to function without a constant sense of inadequacy. Yet, hypersensitivity in various genders produces similar outcomes. 
Communication by mail, a nightmare in many respects, due to its quantity, enables students to engage in genuine and useful tasks of making arrangements in English. As a non-native speaker of Czech in the Czech Republic, I resort to English. I do respond to their mail in Czech/Slovak in English, though, but it is up to them to choose the language they want to use for our correspondence. Nonetheless, I advocate communicating in English, even when the teacher speaks the native language of the student(s), for to some of them it might be the only opportunity to practice the skill. Additionally, under distant learning feedback is provided usually in a written form. There is no reason why this practice should not continue while coming back to the in-class mode, yet for the lack of time that does not usually occur in my practice. In the case of the face-to-face classes I usually praise and critically evaluate students' work orally.

Last but not least, the online sessions help create a more egalitarian atmosphere, starting with the layout. In the university classrooms at my disposal there are rooms with tables arranged in a semi-circle, but I am also required to teach in places arranged in a traditional way with desks in rows. In both cases the teacher's place is in the front, remote from the other seats, and also it often is a chair of higher quality than the remaining ones. Even in the former, more modern distribution, the physical distance perpetuates the psychological separation and clearly illustrates different roles: the space is designed in such a way that Ss and $\mathrm{T}$ confront each other. On zoom, notwithstanding, all the actors are granted the same space, design and "comfort" on the screen. Furthermore, addressing each other by first name is rendered easier due to these showing under the picture/video of each person present. Thanks to the latter introducing the convention of calling people by their first name, common in the English speaking culture, proves an easier task: Ss see the teacher's first name throughout the year, devoid of any titles preceding it, and thus many seem to grow more confident when it comes to approaching them.

In conclusion, online learning does present certain benefits that supersede the sessions when we meet in person. However, it seems that the majority of students express the wish they could join the classes at the university, as usual. On the other hand, they do not necessarily miss the actual learning in a particular class, but interaction with peers and the scholarly ambience that the university as an institution emanates. Nonetheless, I strongly believe that preserving certain elements of the online mode would prove constructive. Therefore, I would advocate a substantial increase in the number of blended-learning courses to cater for the needs of various learning styles, personal preferences, difficulties, including attention deficit and character traits. 


\section{References}

LEntzner, K. R. (1979). Community Language Learning for Bilingual Students. Journal of Reading. doi: www.jstor.org/stable/40028784

Matlen, T. (n.d.). The Queen of Distraction. New Harbinger Publications.

PeEters, K. (2020). The Place and Importance of Mediation in Language Learning and Teaching. online seminar. Accessed 8-9. December 2020, https://epale.ec.europa.eu/en/private/ mediation-language-learning-and-teaching/millat-online-seminar

\section{Author}

Mgr. Aleksandra Holubowicz, e-mail: Aleksandra.Holubowicz@ff.cuni.cz

is currently employed at the Language Center of the Faculty of Arts, Charles University. She is an experienced teacher who has taught in various types of schools - public middle school and high schools in Poland and language schools, also in the Czech Republic. She specializes in teaching speaking skills. As for her education, she received her BA in English Philology: Teaching English as A Foreign Language from Gdansk University, Poland. Later she earned her MA in American Studies at Warsaw University. After graduation she enrolled for a philological doctoral program at Gdansk University. Now she is working on her dissertation in comparative literature and hopes to finish it soon. 